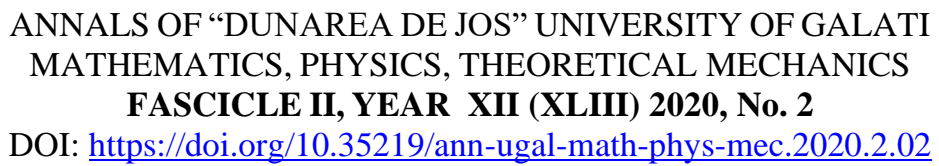

\title{
Nutrient stocks study in agroecosystems located near the steel industry, Galati, Romania
}

\author{
Sorina-Simona Arbanas (Moraru) ${ }^{1,2}$, Antoaneta Ene ${ }^{1,2,3}$ \\ l "Dunarea de Jos" University of Galati, Doctoral School of Mechanical and Industrial Engineering, 47 \\ DomneascaStreet, 800008, Galati, Romania \\ ${ }^{2} I N P O L D E$ interdisciplinary research network, ReForm-UDJG Platform, Dunarea de Jos University of Galati, \\ 111 Domneasca St., 800201 Galati, Romania \\ 3 "Dunarea de Jos" University of Galati, Faculty of Sciences and Environment, Chemistry, Physics and \\ Environment Department, 111 Domneasca Street, 111, 800201, Galati, Romania
}

\begin{abstract}
It is well known the role of nutrients in growing crops and obtaining cost-effective production, but also to ensure a nutritious contribution to humans and animals alike, in food safety conditions. This study aims to evaluate both the supply of nutrients and the main parameters of agricultural soils, in 0-30 cm layer, under intensive agricultural practices pressure, undertaken in an agricultural area influenced by steel industry activities. The soil samples were collected from three sites and different plots grown with wheat, corn, and sunflower, and subjected to analysis protocols within Galati County Soil Survey Office. Soil supply with the main macronutrients indicates imbalances in all studied sites, regardless of the cultivated plants. Overall, soils have a high nitrogen deficiency, correlated with the low level of soil organic matter supply. Total Kjeldahl nitrogen values are between $0.076-0.258 \%$ for all surveyed plots. Mobile phosphorus is low to very high (8-276 ppm), while mobile potassium is low to very high $(70-600 \mathrm{ppm})$. On the one hand, this is due to the natural process of soil degradation through water and wind erosion, and on the other to anthropogenic activities. Most of the time, out of the desire to obtain large harvests, farmers apply non-compliant amounts of fertilizers, which translates into the physical and chemical degradation of agricultural soils and poor management of crop nutrition. Other investigated soil parameters were $\mathrm{pH}$, particle size fractions, as they are related to the dynamics of chemical elements in the soil. It could be concluded that the studied agricultural soils are characterized by imbalances in terms of providing chemical elements accessible to plants, in relation to the main investigated physico-chemical parameters and environmental conditions.
\end{abstract}

Keywords: macronutrients, industrial area, soil fertility,agroecosystems, iron and steel, Galati

\section{INTRODUCTION}

Nitrogen $(\mathrm{N})$, phosphorus $(\mathrm{P})$, and potassium $(\mathrm{K})$ are essential macroelements in plant nutrition, along with calcium, magnesium, and sulfur. They are considered nutrients without which the vegetative cycle cannot take place. Imbalances in plant nutrition, in different stages of evolution, generate crop production losses and decrease their quality [1]. Between soil macronutrients and microelements, there is a synergistic relationship, the deficiency or excess of one of them causing disturbances of fixation and availability of the others [2]. Higher concentrations of $\mathrm{N}, \mathrm{P}$, and $\mathrm{K}$ are often found in the upper layer of the soil and gradually decrease to depth [3]. Periodic assessment of the soil physico-chemical parameters is important in maintaining its health and of the entire ecosystem alike. Therefore, the present study aims at a preliminary assessment of macronutrient concentrations in soils cultivated with wheat, maize, and sunflower. 
Sendreni, Tulucesti, and Vadeni territories are part of the South-East Development Region, Romania, the share of arable land representing more than $80 \%$ of the total agricultural area. According to report [4], the area of the main categories of land use is shown in Table 1 and Figure 1.

Table 1. Main categories of land use surfaces [4]

\begin{tabular}{|c|c|c|c|c|c|c|c|c|c|c|}
\hline Territory & $\begin{array}{c}\text { Agricultural } \\
\text { area }\end{array}$ & \multicolumn{2}{|c|}{ Arable } & \multicolumn{2}{c|}{ Pasture } & \multicolumn{2}{c|}{ Vineyard } & \multicolumn{2}{|c|}{ Orchard } \\
\hline & ha & ha & $\%$ & ha & $\%$ & ha & $\%$ & ha & $\%$ \\
\hline \multicolumn{8}{|c|}{ Galati county } \\
\hline Sendreni & 3923 & 3398 & 86.62 & 250 & 6.37 & 80 & 2.04 & 195 & 4.97 \\
\hline Tulucesti & 5947 & 5067 & 85.20 & 247 & 4.15 & 633 & 10.64 & 0 & 0.00 \\
\hline \multicolumn{8}{|c|}{ Braila county } \\
\hline Vadeni & 11188 & 10605 & 94.79 & 538 & 4.80 & 31 & 0.28 & 14 & 0.13 \\
\hline
\end{tabular}

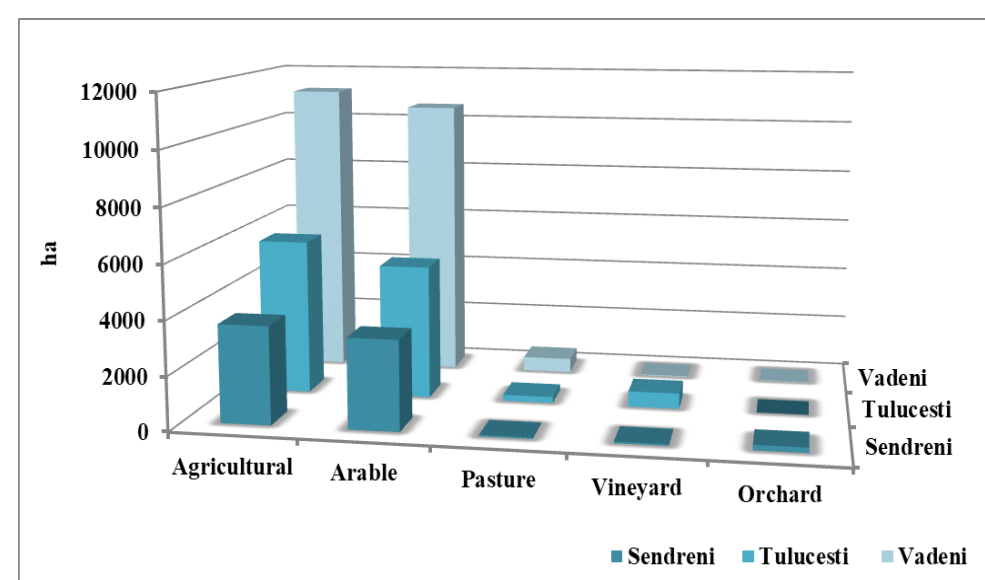

Fig. 1. Agricultural areas structure and surface by the main categories of land use

Statistics show that, among agricultural crops, the most cultivated are wheat, corn, and sunflower. The total cultivated area by crops for each studied territory is presented in Table 2 and Figure 2.

Table 2 Cultivated area for the main field crops [4]

\begin{tabular}{|c|c|c|c|}
\hline \multirow{2}{*}{ Territory } & Wheat and rye & Corn & Sunflower \\
\cline { 2 - 4 } & \multicolumn{3}{|c|}{ ha } \\
\hline Sendreni & 125 & 1016 & 773 \\
\hline Tulucesti & 1030 & 2053 & 880 \\
\hline Vadeni & 1495 & 3109 & 2302 \\
\hline
\end{tabular}

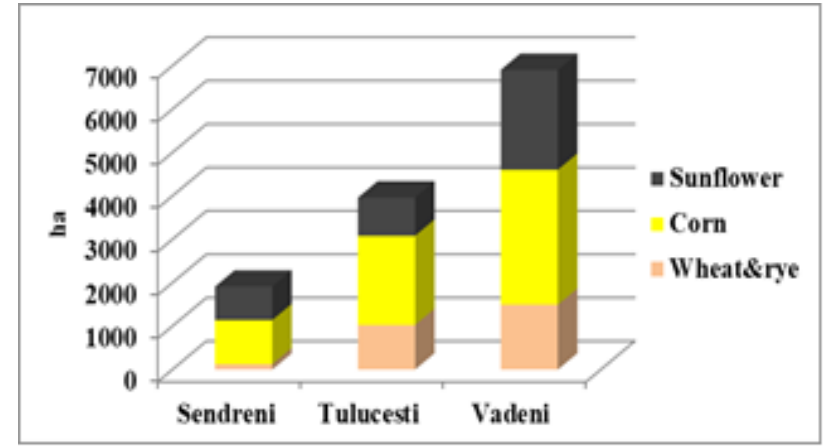

Fig. 2 Main crop plants area 


\section{EXPERIMENTAL}

\subsection{Sampling site location}

The study of soil nutrients was carried out in three agricultural territories from the SE Romania (Tulucesti and Sendreni, Galati county, and Vadeni, Braila county). They are located in the plain and meadow area, in a temperate continental climate and steppe region.

\subsection{Sampling procedure}

The soils were taken from agricultural lands cultivated with wheat, corn, and sunflower, on a depth of 0-30 cm. A total number of 29 samples were collected in encoded plastic bags $(12$ samples from Tulucesti, 8 samples from Sendreni, and 9 samples from Vadeni). Field activity took place in July, September, and October 2018 and 2019, and sampling points were established according to the local ecological conditions and the area of influence of the Galati steel plant.

\subsection{Soil samples preparation and testing}

Soil samples were conditioned and air-dried, ground in a porcelain mortar, and passed through a $2 \mathrm{~mm}$ sieve. Investigations on chemical parameters were performed in the laboratory of Galati County Soil Survey Office, according to the methods provided in Table 3.

Table 3. Analytical methods used to determine the chemical parameters of the soil

\begin{tabular}{|l|l|}
\hline Parameter & Analytical method \\
\hline $\mathrm{pH}$ & Potentiometric in aqueous suspension 1: 2.5 (SR ISO 10390) \\
\hline Organic matter (OM) & Volumetric method (STAS 7184/21-82) \\
\hline Organic carbon (OC) & Volumetric method (STAS 7184/21-82) \\
\hline $\begin{array}{l}\text { Total Kjeldhal nitrogen } \\
(\mathrm{TKN})\end{array}$ & Kjeldhal method (SR ISO 11261) \\
\hline Mobile phosphorus $\left(\mathrm{P}_{\mathrm{m}}\right)$ & $\begin{array}{l}\text { Egner-Riehm-Domingo method, in ammonium lactate acetate (AL) } \\
\text { extraction at pH 3.7 and UV-VIS Spectrometry (SR ISO 11263) }\end{array}$ \\
\hline Mobile potassium $\left(\mathrm{K}_{\mathrm{m}}\right)$ & $\begin{array}{l}\text { Egner-Riehm-Domingo method, in ammonium lactate acetate (AL) } \\
\text { extraction at pH 3.7 and Flame Atomic Emission Spectrometry } \\
\text { (STAS 7184/18-80) }\end{array}$ \\
\hline Particle-size analysis & Gravimetric method (STAS 7184/10-79) \\
\hline $\begin{array}{l}\text { Sum of exchangeable } \\
\text { bases (SB) }\end{array}$ & Kappen method \\
\hline Hydrolytic acidity (Ha) & Volumetric method (extraction with 1N sodium acetate) \\
\hline
\end{tabular}

Nitrogen index was calculated as follows:

$$
\mathrm{NI}=\left(\mathrm{H} \mathrm{x} \mathrm{V}_{\mathrm{Ha}}\right) / 100 \text {, where: }
$$

NI- nitrogen index $(\%)$;

$\mathrm{H}$ - humus content (\%);

$\mathrm{V}_{\mathrm{Ha}}$ - the degree of base saturation (\%); it was calculated according to the formula:

$\mathrm{V}_{\mathrm{Ha}}=(\mathrm{SB} /(\mathrm{SB}+\mathrm{Ha})) \times 100$, where:

$\mathrm{V}_{\mathrm{Ha}}$ - the degree of base saturation (\%);

$\mathrm{SB}$ - the sum of exchangeable base (me/100 g soil);

$\mathrm{Ha}$ - hydrolytic acidity (me/100 g soil). 


\section{RESULTS AND DISCUSSION}

\subsection{Soil pH}

Soil reaction influences the bioavailability of nutrients and may induce restrictions on plant development [5]. In general, the results showed that the $\mathrm{pH}$ of the investigated soils did not vary within very wide limits, being from slightly acid to moderately alkaline. The results show that in the Tulucesti area, soils' $\mathrm{pH}$ is slightly acid (6.35-6.60), slightly alkaline (7.52-8.36), and moderately alkaline (8.42). In the Sendreni area, $\mathrm{pH}$ values are similar to those in Tulucesti, the soils evolving on the same type of parent material and in the same ecological conditions. Soil reaction is slightly acid (6.34), slightly alkaline (7.85-8.02), and moderately alkaline (8.44-8.49). Soils from Vadeni, developed in the meadow area of the Siret-Danube river system, are characterized mostly by a slightly alkaline reaction (8.06-8.34) and moderately alkaline reaction (8.46). Soil pH and its spatial distribution by classes are shown in Fig. 3 a), b), c).

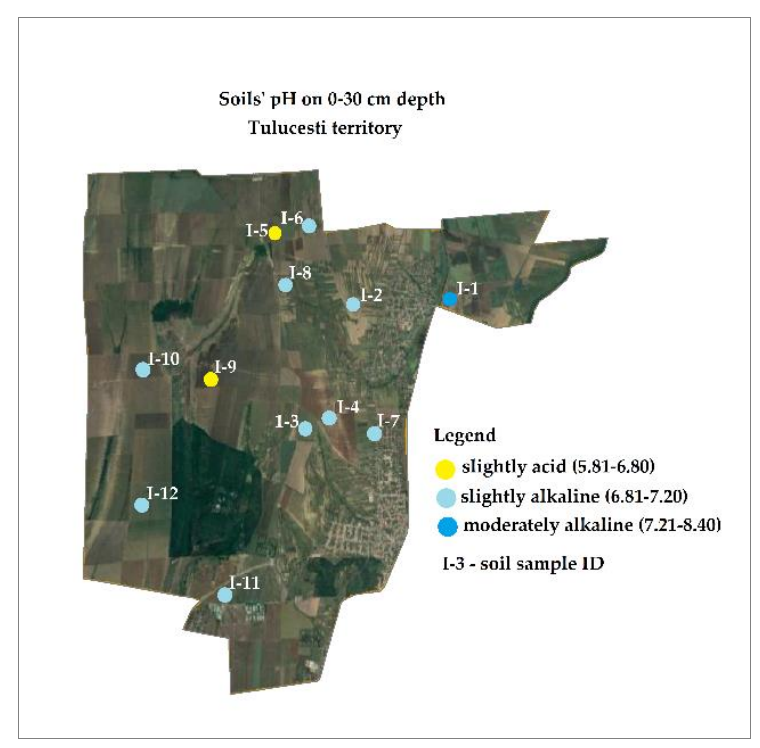

a)

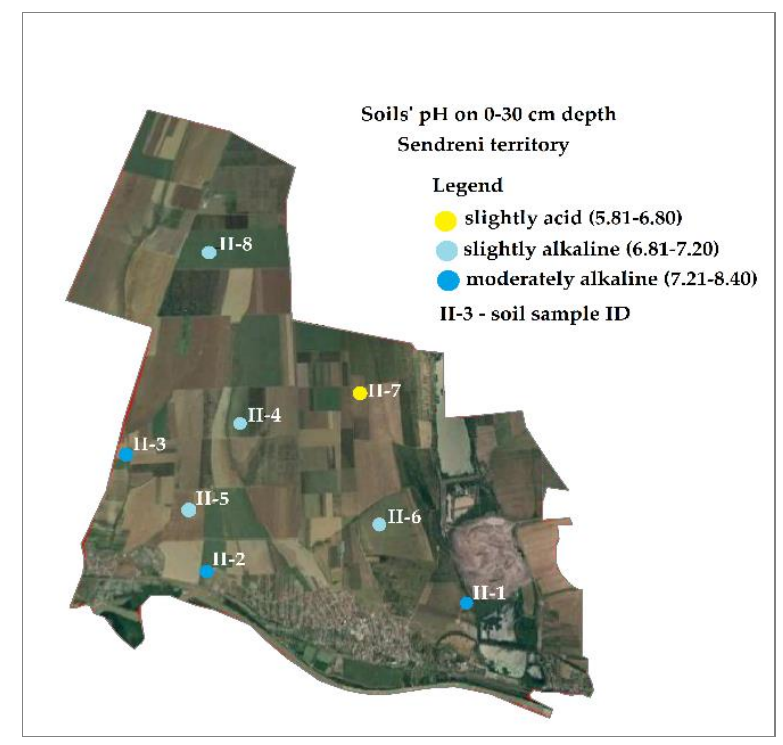

b)

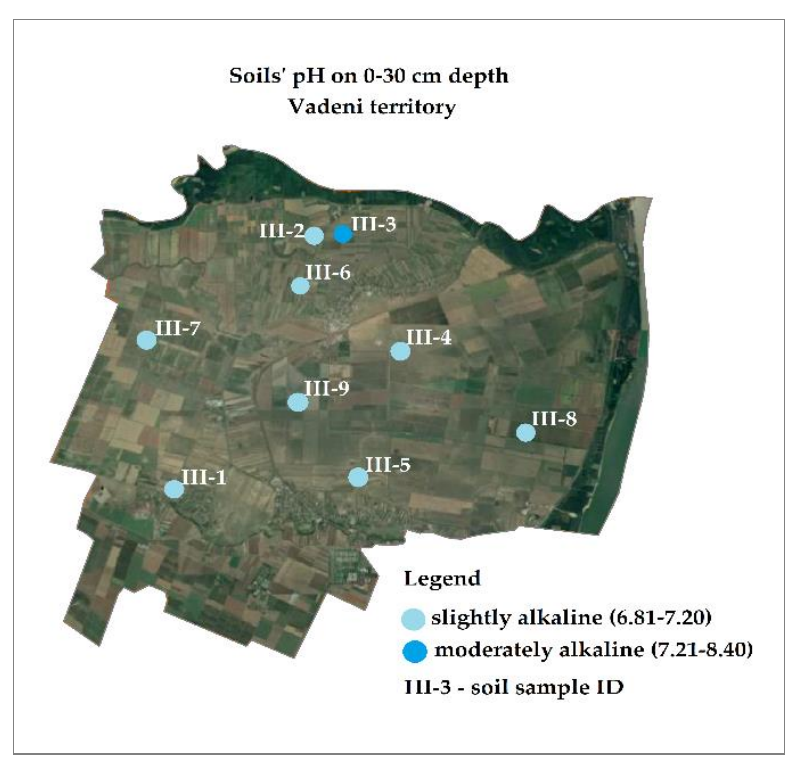

c)

Fig. 3. Soils' reaction on 0-30 cm depth: a) Tulucesti, b) Sendreni, c) Vadeni territory 


\subsection{Soil texture}

Figure 4 a), b), c) show the particle size composition of the investigated agricultural soil. In direct relation to the parent material, the soil texture plays an important role in the infiltration of water into the soil and / or the migration of nutrients or toxic elements in the lower layers.

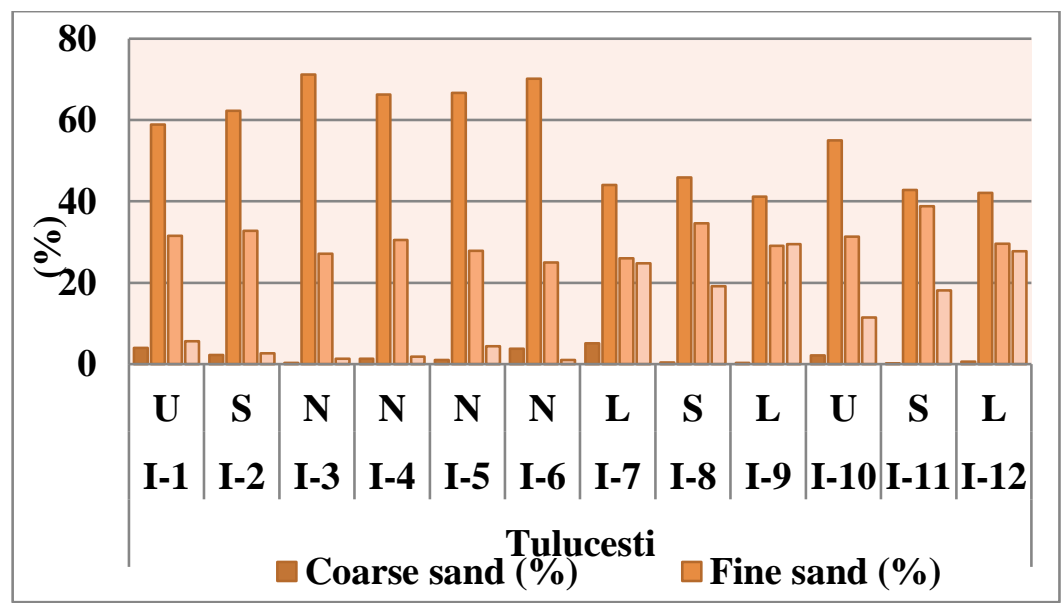

a)

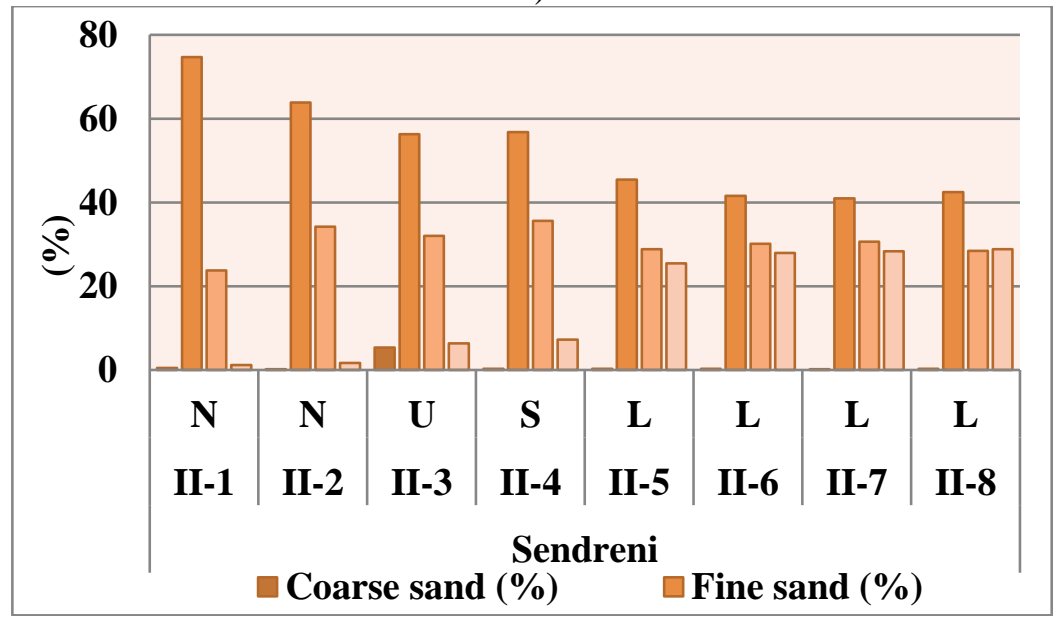

b)

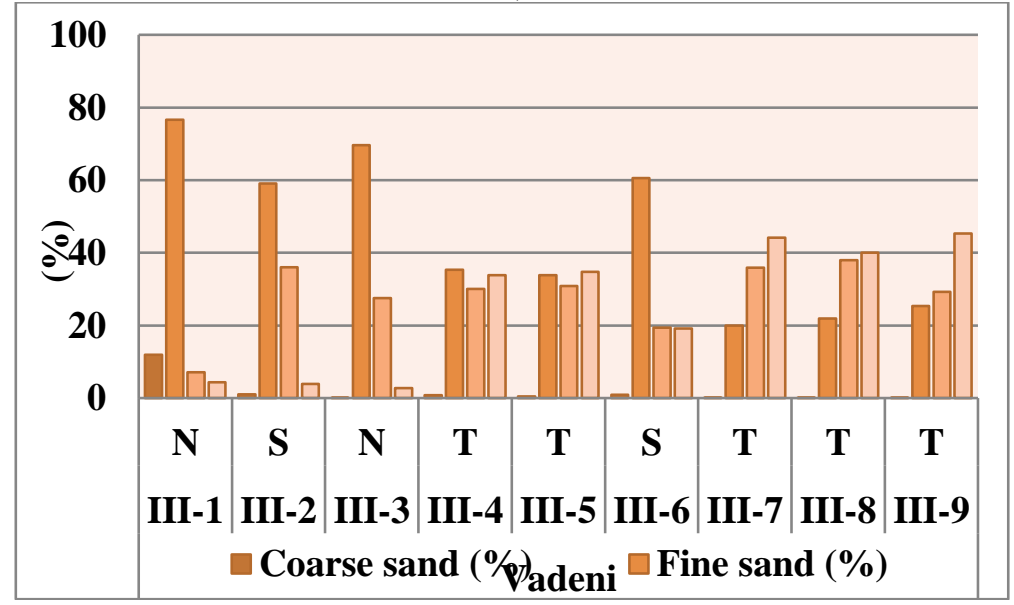

c)

Fig. 4 Granulometric fractions of soils: a) Tulucesti, b) Sendreni, c) Vadeni territory 
Sandy soils are prone to loss of nutrient reserves and water needed by plants, while clay soils have the ability to store more water and nutrients, but block them so that they cannot be made available to plants [6]. Soils from Tulucesti and Sendreni territories are of coarse (sand $(\mathrm{N})$ and sandyloam (U)) and medium (loamy-sand (S) and loam (L)) texture. On Vadeni territory, the texture is mostly medium-fine (loamy-clay (T)), while medium (loamy-sand (S)) and coarse (sand (N)) classes are present in narrow surfaces.

\subsection{Organic matter and organic carbon content}

Organic matter $(\mathrm{OM})$ is an indispensable component for ensuring soil fertility, its presence being a mandatory condition for plant nutrition. The concentration of organic matter in the soil is related to the amount of organic carbon (OC), as an indicator of soil stability, nutrients, and water supply [7]. Table 4 and Fig. 5 present analytical results for OM, OC, C/N ratio, and TKN.

Table 4. Organic matter, organic carbon, $\mathrm{C} / \mathrm{N}$ ratio, and the Kjeldhal nitrogen content in soil, on 0-30 cm depth, Tulucesti, Sendreni (Galati county) and Vadeni (Braila county) territories

\begin{tabular}{|l|c|c|c|c|c|c|c|c|c|c|c|c|}
\hline \multirow{2}{*}{ Parameter } & \multicolumn{10}{|c|}{ Tulucesti } \\
\cline { 2 - 14 } & I-1 & I-2 & I-3 & I-4 & I-5 & I-6 & I-7 & I-8 & I-9 & I-10 & I-11 & I-12 \\
\hline OM (\%) & 3,51 & 3,38 & 2,11 & 1,71 & 2,46 & 1,87 & 2,27 & 2,14 & 3,30 & 1,79 & 1,68 & 1,63 \\
\hline OC (\%) & 2,04 & 1,96 & 1,22 & 1,00 & 1,43 & 1,09 & 1,32 & 1,96 & 1,92 & 1,04 & 0,98 & 0,95 \\
\hline TKN (\%) & 0,24 & 0,21 & 0,10 & 0,12 & 0,15 & 0,10 & 0,16 & 0,13 & 0,13 & 0,09 & 0,08 & 0,08 \\
\hline C/N & 8,60 & 9,60 & 11,95 & 8,05 & 9,40 & 11,20 & 10,85 & 11,30 & 17,35 & 13,35 & 13,40 & 14,50 \\
\hline
\end{tabular}

\begin{tabular}{|l|c|c|c|c|c|c|c|c|c|c|}
\hline \multirow{2}{*}{ Parameter } & \multicolumn{10}{|c|}{ Sendreni } \\
\cline { 2 - 11 } & I-1 & I-2 & II-1 & II-2 & II-3 & II-4 & II-5 & II-6 & II-7 & II-8 \\
\hline OM (\%) & 3,51 & 3,38 & 1,57 & 1,64 & 0,98 & 1,32 & 2,78 & 2,85 & 2,64 & 2,96 \\
\hline OC (\%) & 2,04 & 1,96 & 0,91 & 0,95 & 0,57 & 0,77 & 1,62 & 1,66 & 1,53 & 1,72 \\
\hline TKN $(\%)$ & 0,24 & 0,21 & 0,11 & 0,12 & 0,14 & 0,08 & 0,12 & 0,13 & 0,17 & 0,11 \\
\hline C/N & 8,60 & 9,60 & 7,75 & 8,15 & 6,20 & 21,95 & 15,80 & 15,80 & 10,25 & 18,90 \\
\hline
\end{tabular}

\begin{tabular}{|l|c|c|c|c|c|c|c|c|c|}
\hline \multirow{2}{*}{ Parameter } & \multicolumn{10}{|c|}{ Vadeni } \\
\cline { 2 - 10 } & III-1 & III-2 & III-3 & III-4 & III-5 & III-6 & III-7 & III-8 & III-9 \\
\hline OM (\%) & 2,27 & 2,17 & 1,67 & 2,50 & 1,91 & 1,20 & 3,13 & 2,23 & 2,16 \\
\hline OC (\%) & 1,32 & 1,26 & 0,97 & 1,45 & 1,11 & 0,69 & 1,82 & 1,29 & 1,25 \\
\hline TKN (\%) & 0,11 & 0,14 & 0,11 & 0,12 & 0,08 & 0,11 & 0,13 & 0,14 & 0,10 \\
\hline C/N & 11,75 & 9,25 & 8,85 & 14,00 & 17,00 & 7,10 & 16,35 & 10,65 & 16,40 \\
\hline C/N=10 (calcic mull ); C/N=12-15 (non-calcic mull ); C/N=15-25 (moder) $[2]$ \\
\hline
\end{tabular}

The data highlight that, depending on the particle size composition (Fig. 4 a), b), c)) and the content of organic matter (Table 4), investigated soils fall into the following content classes [8]:

- in the Tulucesti area, the values of the humus content vary between $1.63 \%$ and $3.51 \%$, so that the concentration falls within the low-high classes.

- in the Sendreni area, the humus content is between $0.98 \%-2.85 \%$, low-moderate classes respectively.

-in the Vadeni area, the humus concentration in soil shows values of $1.20 \%-3.13 \%$, low-high classes.

[2] and [9] suggest that the values of soil organic matter are 1.724 times higher than those of organic carbon, as shown in Table 4. 


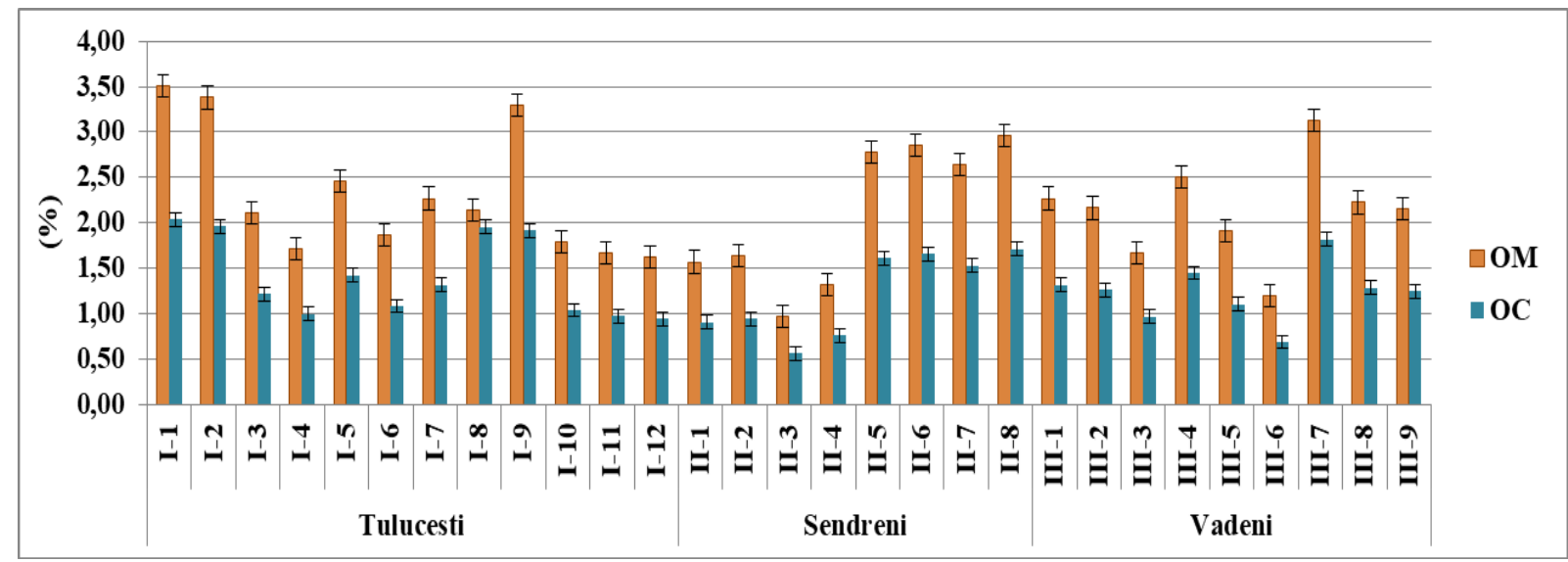

Fig. 5. Organic matter and organic carbon level in agricultural soils' top layer, Tulucesti, Sendreni, and Vadeni areas

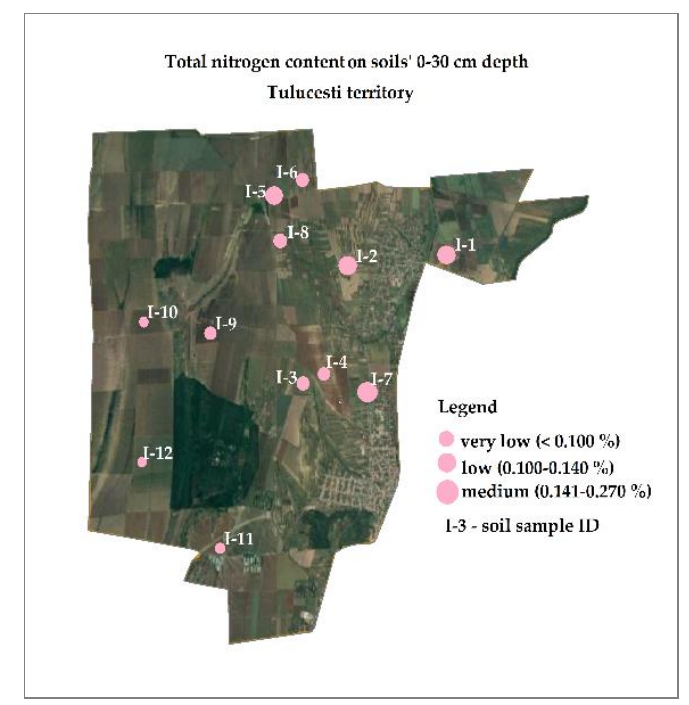

a)

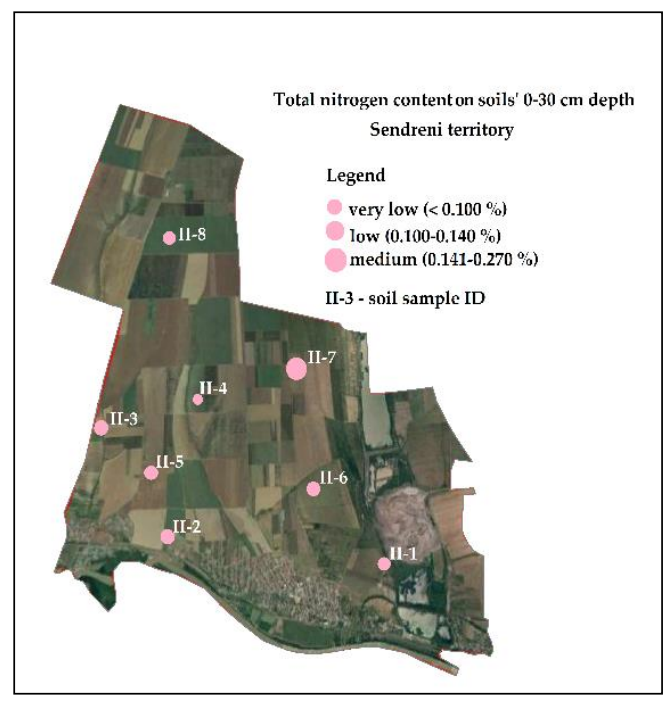

b)

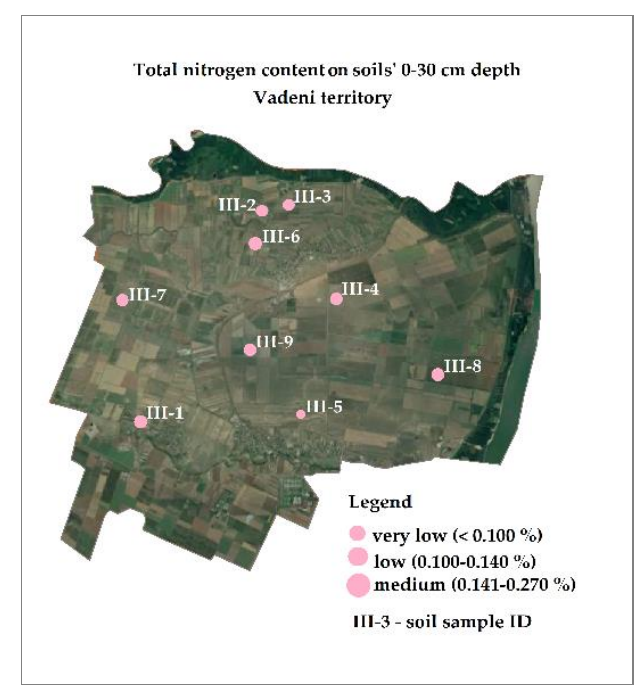

c)

Fig. 6. Total Kedjdahl nitrogen content in soil, on 0-30 cm depth: a) Tulucesti, b) Sendreni, c) Vadeni areas 
$\mathrm{C} / \mathrm{N}$ ratio highlights the type of humus on the $0-30 \mathrm{~cm}$ depth of arable land soils. Therefore, on the territory of Tulucesti, $\mathrm{C} / \mathrm{N}$ values indicate especially the presence of calcic and non-calcic mull humus type, which is correlated with the soil types in the sampling area (calcaric chernozems and fluvisols and cambic chernozems [10 a]). In Sendreni, the soils consist of calcic mull and moder type of humus, on calcaric chernozems $[10 \mathrm{~b}]$. On Vadeni territory, the soils contain calcic and non-calcic mull, but also moder humus, on fluvisols and gleysols [11].

\subsection{Total Kjeldhal nitrogen concentration}

Total Kjeldhal nitrogen content of agricultural soils from Tulucesti, Sendreni, and Vadeni areas is presented in Table 4 and Fig. 6 a), b), c).

Considering the limits of the interpretation given by [2], the studied soils fall within the very low-medium limits supplied with total nitrogen. The agricultural layer of soils on the territory of Tulucesti presents average values of $0.08-0.24 \%$, most of the analyzed samples having a very low and low supply of TKN. The soils on Sendreni territory have average concentrations of 0.08-0.17\% nitrogen, generally being low supplied with this element. On Vadeni territory, the soils have a very low and low content of TKN, registering average values of $0.08-0.14 \%$. According to [12], total nitrogen in the top layer of Romanian soils falls between $0.02 \%$ to $0.77 \%$.

The level of nitrogen content in the soil may be also assessed according to the nitrogen index, [13]. For the studied territories, the values of the nitrogen index are shown in Fig. 7 a), b), c).

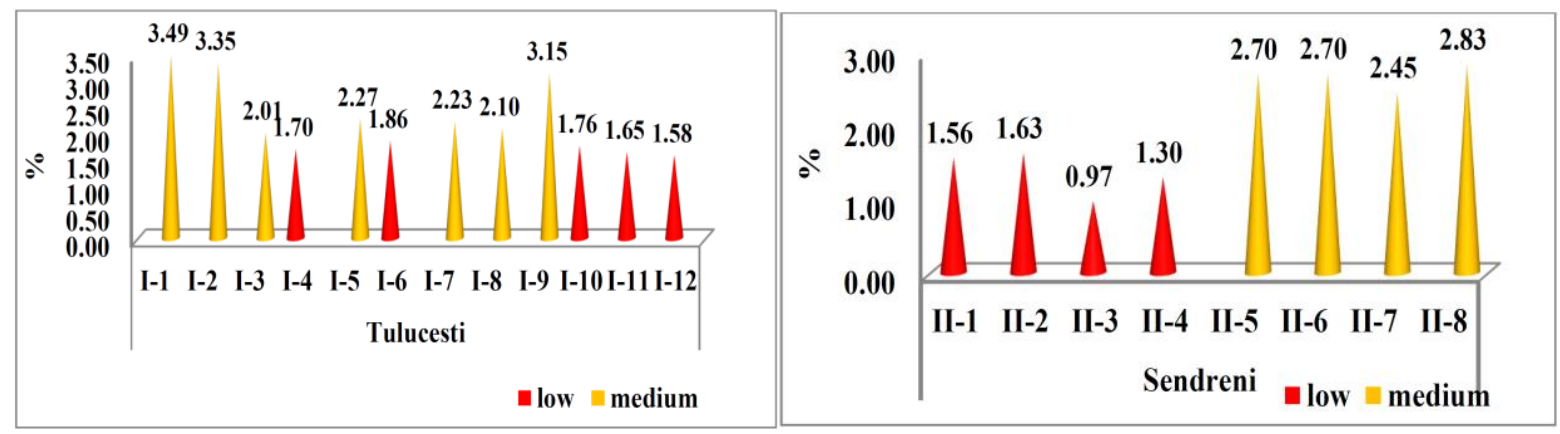

a)

b)

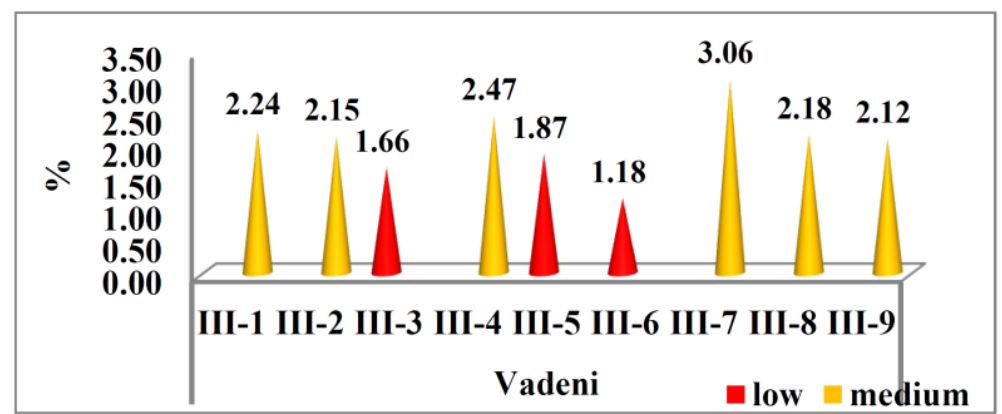

c)

Fig. 7. Nitrogen index in agricultural soils, on 0-30 cm depth: a) Tulucesti, b) Sendreni, c) Vadeni areas 
According to the nitrogen index scale of the interpretation provided by [2] and [13], the soil is low and moderately supplied with nitrogen, the values varying between $1.58-3.49 \%$ on Tulucesti territory, $0.97-2.83 \%$ on Sendreni territory, and $1.18-3.06 \%$ on Vadeni territory.

\subsection{Mobile phosphorus}

Regular checking of mobile phosphorus level in soil, along with other nutrients, is important for the proper management of nutrient reserves, so as to ensure the necessary amount for the development of metabolic functions of plants. For the 0-20 cm layer of soils in Romania [12] reported values located in the extremely low-very high range, with the predominance of the extremely low-low category. The status of soils' mobile phosphorus of the three studied territories is shown in Fig. 8 a), b) c).

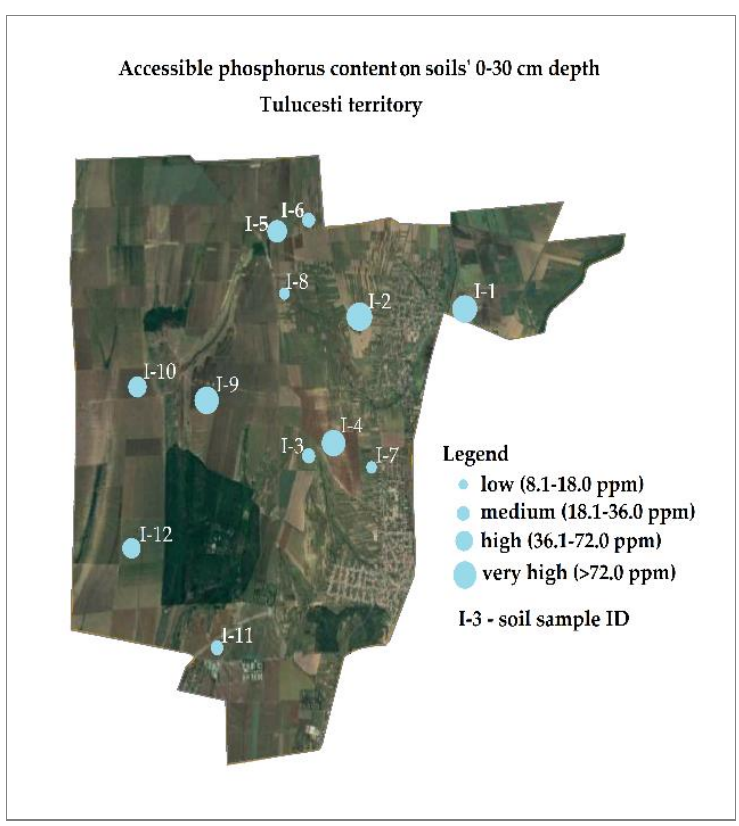

a)

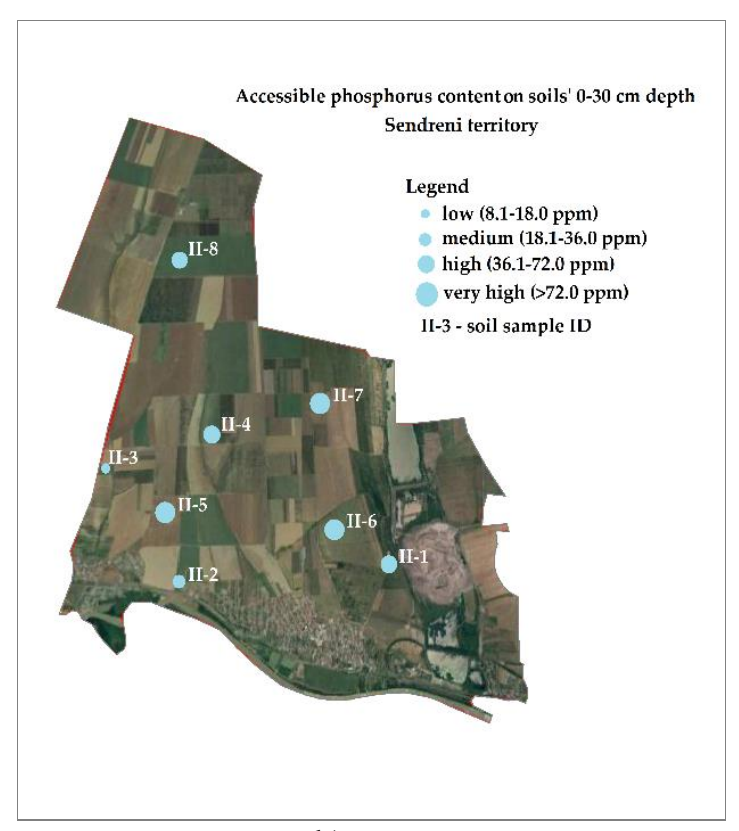

b)

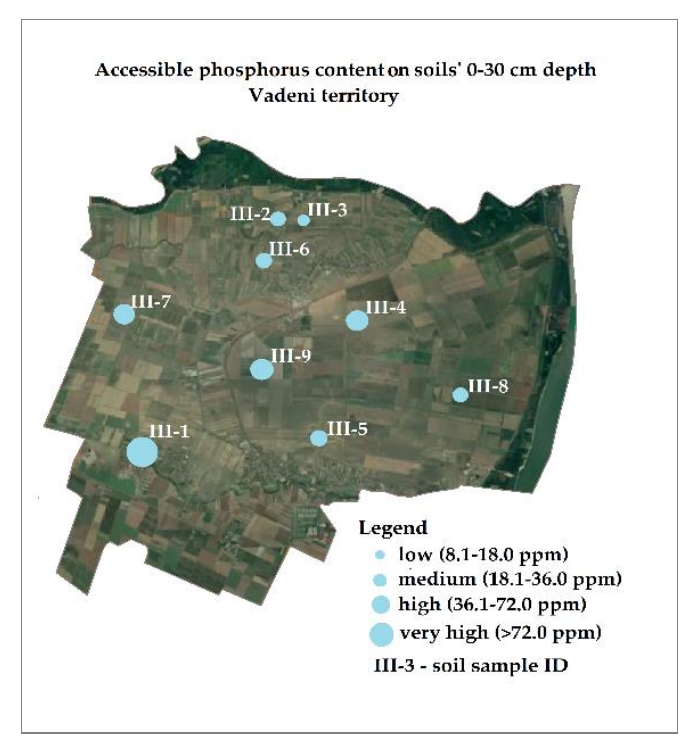

c)

Fig. 8. Mobile phosphorus content in the soil, on 0-30 cm depth: a) Tulucesti, b) Sendreni, c) Vadeni areas 
The level of mobile phosphorus supply of agricultural soils on the three studied territories is from low to very high. The soils from Tulucesti show values from $11.30 \mathrm{ppm}$ to $253.35 \mathrm{ppm}$. On Sendreni territory the content is $9.80 \mathrm{ppm}-161.75 \mathrm{ppm}$, and on Vadeni territory, it ranges between 14.85-180.30 ppm.

Recent studies have shown the importance of correcting phosphorus deficiencies in the soil, especially since this element is involved in the efficiency of nitrogen fixation and further in biomass production $[14,15]$, stimulating root development and, implicitly, increasing the amount of organic matter in the soil.

\subsection{Mobile potassium}

In Fig. 9 a), b), c) it may be observed that the mobile potassium concentration in the agricultural soils is in the medium-very high limits, with values between $95-600 \mathrm{ppm}$.

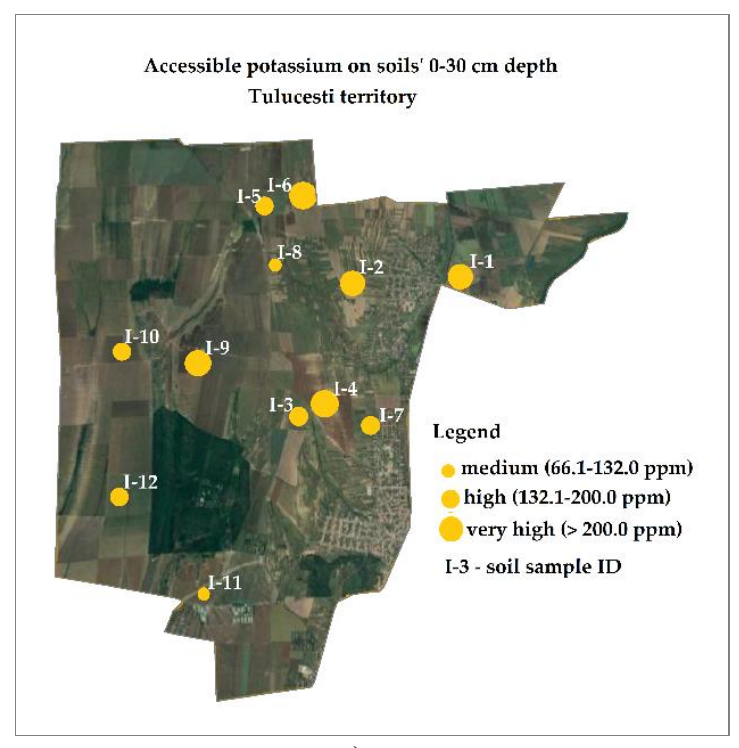

a)

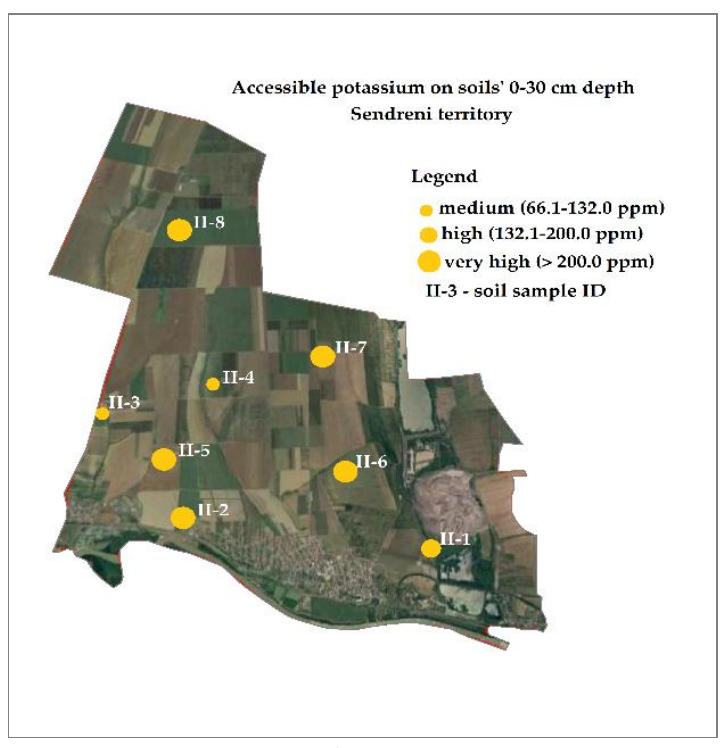

b)

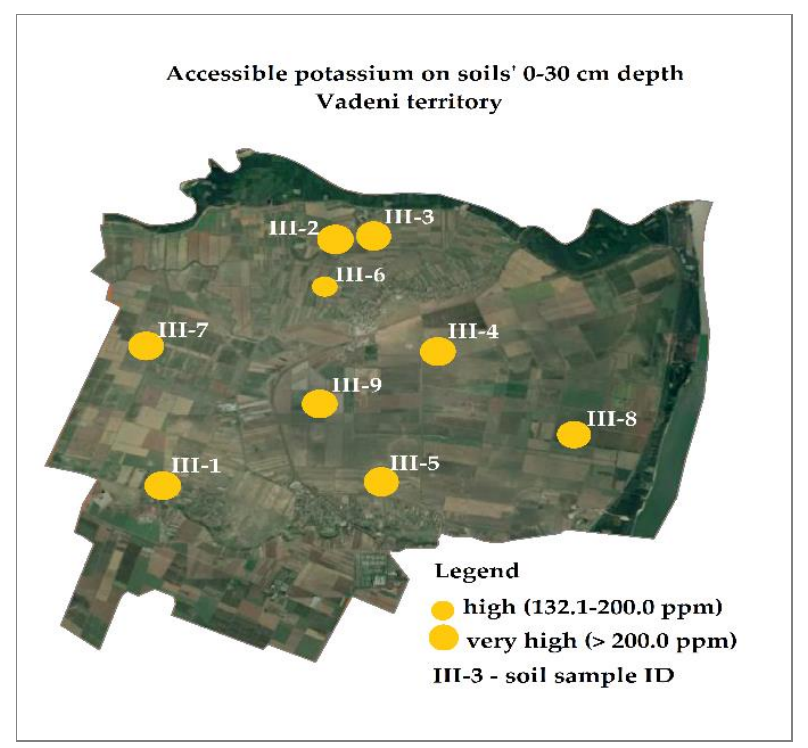

c)

Fig. 9. Mobile potassium content in the soil, on 0-30 cm depth: a) Tulucesti, b) Sendreni, c) Vadeni areas 
For the territories of Tulucesti and Sendreni, the level of supply with mobile potassium is medium-very high, with 112 - $600 \mathrm{ppm}$ for Tulucesti and, 95 - $600 \mathrm{ppm}$ for Sendreni, respectively. On the territory of Vadeni, the concentration of mobile potassium in the 0-30 cm layer reaches 170-506 ppm, falling within the high-very high limits. According to [12] the level of mobile potassium in Romania's agricultural soils, on 0-20 cm layer, is within the extremely low-very high limits.

\section{CONCLUSIONS}

Long periods of agricultural use of the land requires careful attention in soil resources management and environmental protection. The content of TKN, mobile $\mathrm{P}$, and $\mathrm{K}$ was investigated, as they are elements involved in all the functional processes in plants. The studied soils have nutrient deficiencies. Under these conditions, improvement measures through controlled fertilization, with organic and chemical fertilizers are required, at the same time with the application of irrigation and agrotechnical works to improve the physical properties of the soils.

Acknowledgements: The authors would like to thank the funding of project BSB27-MONITOX (2018-2021), Joint Operational Programme Black Sea Basin 2014-2020, as well as project no. 71/2020 and grant no. 32/2020 of Joint Institute for Nuclear Research at Dubna.

\section{References}

1. Tripathi D.K., Singh V.P., Chauhan D.K., Prasad S.M., Dubey N.K., Role of macronutrients in plant growth and acclimation: recent advances and future prospective, Chapter in Improvement of Crops in the Era of Climatic Changes (Ahmad P., Wani M., Azooz M., Phan Tran LS., Eds.), Springer, New York, NY, pp 197-216, 2014. https://doi.org/10.1007/978-14614-8824-8_8

2. Rusu M., Marghitas M., Oroian I., Mihaiescu T., Dumitras A., Tratat de agrochimie, Ceres, Bucuresti, Romania, p.164, 2005.

3. Fageria N., Moreira A., The role of mineral nutrition on root growth of crop plants, Chapter in: Advances in Agronomy, Donald L. Sparks, editor, Burlington: Academic Press, 110, pp 251-331, 2011. https://doi.org/10.1016/B978-0-12-385531-2.00004-9

4. http://statistici.insse.ro/

5. Pessarakli M., Impact of soil pH on nutrient uptake by crop plants, Chapter in: Handbook of plant and crop stress, $2^{\text {nd }}$ edition, Marcel Dekker Inc., New Tork, USA, pp 51-60, 1999.

6. Moraru S.-S., Ene A., Badila A., Physical and hydro-physical characteristics of soil i the context of climate change. A case study in Danube River basin, SE Romania, Sustainability 12 (21) (2020) 9174. https://doi.org/10.3390/su12219174

7. FAO, Soil organic carbon the hidden potential, Wiese L., Alcantara V., Baritz R., Vargas R., Eds., Food And Agriculture Organization Of The United Nations, Rome, Italy, 2017.

8. Lacatusu R., Agrochimie, Helicon, Timisoara, Romania, pp 49, 2000.

9. Nath T.N., Soil texture and total organic matter content and its influences on soil water holding capacity of some selected tea growing soils in Sivasagar District of Assam, India, Int. J. Chem. Sci., 12 (4), 1419-1429, 2014. Available online: https://www.tsijournals.com/articles/soil-texture-and-total-organic-matter-content-and-itsinfluences-on-soil-water-holding-capacity-of-some-selected-tea-gro.pdf (accessed on 14 November 2020).

10. County Soil Survey Office of Galati. Pedological and agrochemical study in order to achieve and update the county soil-land monitoring system for agriculture. a) Tulucesti communal territory, 2020; b) Sendreni communal territory, 2014 (in Romanian).

11. County Soil Survey Office of Braila, Pedological and agrochemical study in order to achieve and update the county soil-land monitoring system for agriculture. Vadeni communal territory village territory, 2018 (in Romanian). 
12. Dumitru M., Dumitru S., Tanase V., Mocanu V., Manea A., Vrânceanu N., Preda M., Eftene M., Ciobanu C., Calciu I., Râşnoveanu I., Monitoringul starii de calitate a solurilor din Romania, Sitech, Craiova, Romania, pp 44, 2011.

13. Budoi Gh., Agrochimie I - Solul si planta, Editura Didactica si Pedagogica, R.A., Bucuresti, Romania, pp 119, 2000.

14. Míguez-Montero M.A., Valentine A., Pérez-Fernández M.A., Regulatory effect of phosphorus and nitrogen on nodulation and plant performance of leguminous shrubs, AoB Plants, 12 (1), plz047, 2020. https://doi.org/10.1093/aobpla/plz047

15. Pérez-Fernández M., Míguez-Montero A., Valentine A., Phosphorus and nitrogen modulate plant performance in shrubby legumes from the Iberian Peninsula, Plants, 8 (9), 334, 2019. https://doi.org/10.3390/plants8090334 